\title{
HIGHER-ORDER NON-LINEAR ANALYSIS OF STEEL STRUCTURES PART II : REFINED PLASTIC HINGE FORMULATION
}

\author{
C.K. Iu ${ }^{*}$ and M.A. Bradford \\ Centre for Infrastructure Engineering and Safety \\ School of Civil and Environmental Engineering \\ The University of New South Wales, UNSW Sydney, NSW 2052, Australia \\ *(Corresponding author: E-mail: iu.jerryu@gmail.com)
}

Received: 31 May 2011; Revised: 10 October 2011; Accepted: 14 November 2011

\begin{abstract}
In the companion paper, a fourth-order element formulation in an updated Lagrangian formulation was presented to handle geometric non-linearities. The formulation of the present paper extends this to include material non-linearity by proposing a refined plastic hinge approach to analyse large steel framed structures with many members, for which contemporary algorithms based on the plastic zone approach can be problematic computationally. This concept is an advancement of conventional plastic hinge approaches, as the refined plastic hinge technique allows for gradual yielding, being recognized as distributed plasticity across the element section, a condition of full plasticity, as well as including strain hardening. It is founded on interaction yield surfaces specified analytically in terms of force resultants, and achieves accurate and rapid convergence for large frames for which geometric and material non-linearity are significant. The solutions are shown to be efficacious in terms of a balance of accuracy and computational expediency. In addition to the numerical efficiency, the present versatile approach is able to capture different kinds of material and geometric non-linearities on general applications of steel structures, and thereby it offers an efficacious and accurate means of assessing non-linear behaviour of the structures for engineering practice.
\end{abstract}

Keywords: Beam-column, Frames, Interaction surface, Material non-linearity, Refined plastic hinge method, Strain hardening

\section{INTRODUCTION}

This paper is concerned with an innovative extension of the geometrically non-linear elastic finite element formulation with a higher-order element, described in the companion paper [1], to include steel yielding so as to produce a robust and highly efficient technique for analysing frames with a multiplicity of component structural members. The material yielding of an infinitesimal steel element or particle across the element section has been investigated numerically through the plastic hinge approach in the efficacious manner.

King et al. [2] presented a plastic hinge method which accounts for the degradation of the member stiffness. The plastic hinge stiffness is formulated in this method by inserting a hinge in the incremental element stiffness equation if a linear initial yield and fixed full yield condition [3] with residual stresses are satisfied. In later work, Liew et al. [4, 5] proposed a second-order refined plastic hinge analysis for steel frame design which included inelastic stiffness degradation, with reference to a bilinear interaction equation AISC [6]. A tangent modulus technique was applied which reduced the modulus of elasticity from its elastic value continuously as it entered the plastic range.

Yau and Chan [7] established a plastic hinge analysis of steel frames in which the hinge stiffness is formulated into the element stiffness matrix based on the incremental moment equation of equilibrium at a node, with the full yield criterion of Duan and Chen [3] being adopted in the formulation. Further, Chan and Chui [8] proposed a method for considering the gradual yielding 
across a cross-section subjected to bending action, for which the axial force was included by reducing the bending moment capacity. More recently, Iu and Chan [9] developed a refined plastic hinge method which included strain-hardening for steel structures subjected to elevated temperatures, while Iu et al. [10] modified a plastic hinge approach in which the interaction of bending and axial actions on the yield surface at elevated temperature was formulated. Using a higher-order element representation, Chan and Zhou [11, 12] presented a large displacement analysis using a plastic hinge approach in which large deflections in the presence of a hinge along the member can be included.

In the companion paper [1], the geometric non-linearities associated with a second-order analysis of an elastic framed structure were discussed. Commonly, material yielding is an important consideration for steel structures at their strength or ultimate limit state, and so generalised numerical non-linear analysis of steel framed structures at their strength limit state necessitates the accurate modelling of both geometric and material non-linearities. Many contemporary steel structures are very large, comprising of a great number members of which many are slender, and despite advances in computational algorithms and computer hardware capabilities, efficient and accurate analyses of these structures is still problematic when material non-linearities have to be considered. In order to provide a solution technique which overcomes these difficulties, the plastic hinge approach is engaged in this paper to provide a balance between efficiency and accuracy. Elasto-plastic hinge methods have been developed and reported by many researchers (e.g. in $[2,7,13])$, but contrary to these, the present paper develops a refined plastic hinge approach to allow for the gradual development of yielding as distributed plasticity across the section to a fully plastic hinge, which admits strain hardening and accounts for the interaction of axial and bending actions. This is an advance on elasto-plastic hinge methods because it allows for a more general description of the materially non-linear behaviour of the steel in terms of force resultants (rather than of stresses in a much less-efficient plastic zone approach). This paper therefore offers a non-linear analysis with accuracy in solution, versatile for vast forms of structures and reliability in convergence for engineering practice.

\section{INTERACTION EQUATIONS FOR YIELDING CRITERION}

In accordance with the so-called "plastic zone method", the yield condition of the steel is examined with respect to each point in the member, and so it is convenient to express the behaviour of the steel in terms of its stress-strain relationship. This technique is valid for all cross-sections along the member once the domain of the numerical integration has been defined. On the other hand, the "plastic hinge method" bases its material modelling on the load-displacement relationship for a beam-column cross-section [3, 6]. This modelling requires interaction equations between bending and axial actions which defined the capacity its cross-sections.

In general, initial yielding within a member occurs well before the fully plastic cross-sectional strength is reached. It depends on both the shape factor for the cross-section $\eta$ and the residual stresses on the cross-section. The initial yield surface $\phi_{y}$, or initial yield interaction equation, may be defined from the bending actions about the major principal axis $M_{x}$, minor principal axis $M_{y}$ and axial force $P$ collected in the vector $\mathbf{f}=\left\{P, M_{x}, M_{y}\right\}^{\mathrm{T}}$ and related by

$\phi_{y}(\mathbf{f})=\frac{P}{0.8 P_{y}}+\frac{\eta_{x} M_{x}}{0.9 M_{p x}}+\frac{\eta_{y} M_{y}}{0.9 M_{p y}}=1$ 
in which the numbers 0.8 and 0.9 in the denominator account for residual stresses, $P_{y}$ is the axial force capacity of the cross-section, and $M_{p x}$ and $M_{p y}$ are its full plastic moments about the major and minor principal axes respectively which have respective shape factors of $\eta_{x}$ and $\eta_{y}$. When $\phi_{y}(\mathbf{f})<1$, the cross-section is taken as elastic. For a doubly-symmetric I-section, a convenient formulation used for the first yield surface is

$\phi_{y}(\mathbf{f})=\frac{P}{0.8 P_{y}}+\frac{1.25 M_{x}}{M_{p x}}+\frac{1.25 M_{y}}{M_{p y}}=1$.

The AISC-LRFD standard [6 provides bilinear interactions for the criterion of full yield in terms of a function $\phi_{p}(\mathbf{f})=1$, but it is known that this is generally conservative for both short beam-columns for which material non-linearities are dominant and for biaxial loading cases. The present formulation therefore adopts the full yield interaction function $\phi_{p}(\mathbf{f})$ proposed by Duan and Chen [3], which defines a continuous convex full yield surface as shown in Fig. 1, with vertices as its intersection with the $P$ axis.

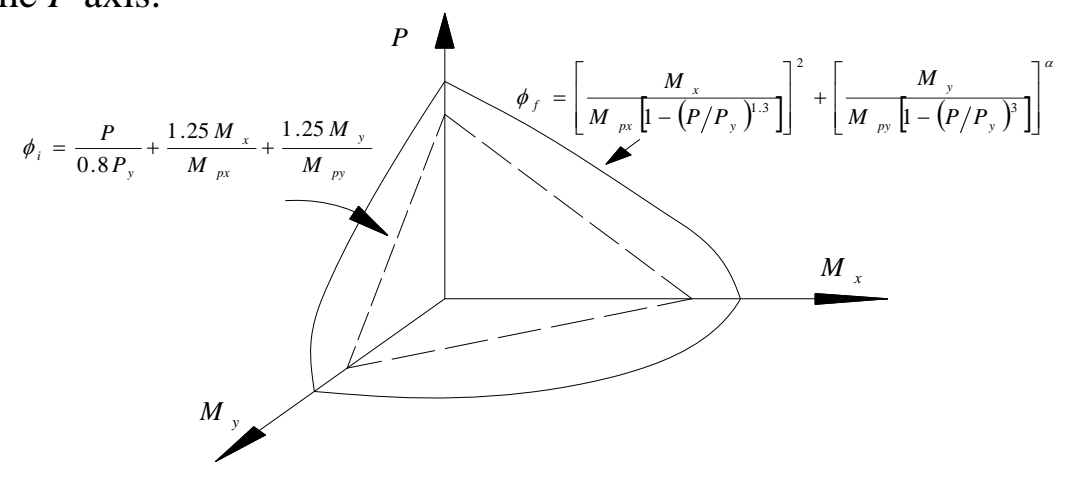

Figure 1. Initial and Full Yield Surface under Interaction of Force Resultants

For the case of uniaxial bending about the major axis, full yield is taken as

$\phi_{p}\left(\left\{P, M_{x}, 0\right\}\right)=\frac{M_{x}}{\bar{M}_{p x}}=\frac{M_{x}}{M_{p x}\left[1-\left(P / P_{y}\right)^{1.3}\right]}=1$,

while for uniaxial bending about the minor axis, it is taken as

$\phi_{p}\left(\left\{P, 0, M_{y}\right\}\right)=\frac{M_{y}}{\bar{M}_{p y}}=\frac{M_{y}}{M_{p y}\left[1-\left(P / P_{y}\right)^{3}\right]}=1$

in which $P_{y}=f_{y} A, A$ is the area of the cross-section, $f_{y}$ is the uniaxial yield stress and the moments $\bar{M}_{p x}$ and $\bar{M}_{p y}$ are the major and minor axis bending capacities reduced in the presence of axial force. A modified interaction surface from Tebege and Chen [14] is

$\phi_{p}(\mathbf{f})=\left(\frac{M_{x}}{\bar{M}_{p x}}\right)^{2}+\left(\frac{M_{y}}{\bar{M}_{p y}}\right)^{\alpha}=1$

so that using Eqs. 3 and 4, 
$\phi_{p}(\mathbf{f})=\left\{\frac{M_{x}}{M_{p x}\left[1-\left(P / P_{y}\right)^{1.3}\right]}\right\}^{2}+\left\{\frac{M_{y}}{M_{p y}\left[1-\left(P / P_{y}\right)^{3}\right]}\right\}^{\alpha}=1$

in which

$\alpha=1.2+2\left(\frac{P}{P_{y}}\right)$

In the refined plastic hinge approach, gradual yielding is defined when the vector of actions on the cross-section $\mathbf{f}$ is such that $\phi_{y}(\mathbf{f})>1$ and $\phi_{p}(\mathbf{f})<1$; this situation is common for beam-columns at their strength limit state. The initial and full yield surfaces shown in Fig. 1 have been shown [3] to be valid for a large range of steel cross-sections under biaxial bending and compression, and provide an empirical basis for the refined plastic hinge approach of this paper.

\section{REFINED PLASTIC HINGE STIFFNESS FORMULATION}

\subsection{Plastic Hinge Spring Stiffness}

The present non-linear analysis for beam-columns relies on plastic hinge springs, as shown in Fig. 2 , to be activated when the vector of actions at a node $\mathbf{f}$ are such that $\phi_{y}(\mathbf{f})$ exceeds unity. When this vector is such that $\phi_{p}(\mathbf{f})$ exceeds unity, the cross-section experiences strain hardening. The stiffnesses of the axial and bending springs are then taken as

$S_{a}=\frac{E A}{L}\left[\frac{1-\phi_{p}(\mathbf{f})}{\phi_{y}(\mathbf{f})-1}+\mu_{a}\right]$

and

$S_{b}=\frac{E I}{L}\left[\frac{1-\phi_{p}(\mathbf{f})}{\phi_{y}(\mathbf{f})-1}+\mu_{b}\right]$

in which the stiffnesses are such that $\infty>S_{a}>0$ and $\infty>S_{b}>0, \mu_{a}$ and $\mu_{b}$ are strain hardening parameters, $E I / L$ is the elastic flexural stiffness of the beam-column and $E A / L$ is its elastic axial stiffness. The spring formulation of Eqs. 8 and 9 was first introduced by Iu et al. [15].

The interaction between the three force resultants in the vector $\mathbf{f}$ has a twofold effect in the refined hinge formulation; it firstly defines the initial yield and fully plastic surfaces by $\phi_{y}(\mathbf{f})=1$ and $\phi_{p}(\mathbf{f})$ $=1$, and it secondly defines the spring stiffness by Eqs. 8 and 9 which are degraded when $\phi_{y}(\mathbf{f})>1$. This kind of gradual yielding by proposed refined plastic hinge approach heralds distributed plasticity across the member section. The spring formulation is therefore able to capture the non-linear material behaviour, including its elastic domain, gradual or partial yielding, full plasticity, strain hardening as well as residual stresses, in the load-deformation relationship for the quartic beam-column finite element. These hinges may be incorporated into the second-order elastic stiffness formulation of the companion paper [1] using the procedures described in [7, 16]. In reference to [15], it is also worth mentioning that the plastic hinges in Eqs. 8 and 9 are versatile 
for different kind materials, once the interaction equations $\phi_{y}(\mathbf{f})$ and $\phi_{p}(\mathbf{f})$ are replaced by the corresponding material failure surfaces.

\subsection{Secant Stiffness in Plastic Hinge Formulation}

In order to combine the plastic hinge spring stiffness formulation with the second-order elastic stiffness formulation for a beam-column element, the incremental equilibrium equation of the element is written as

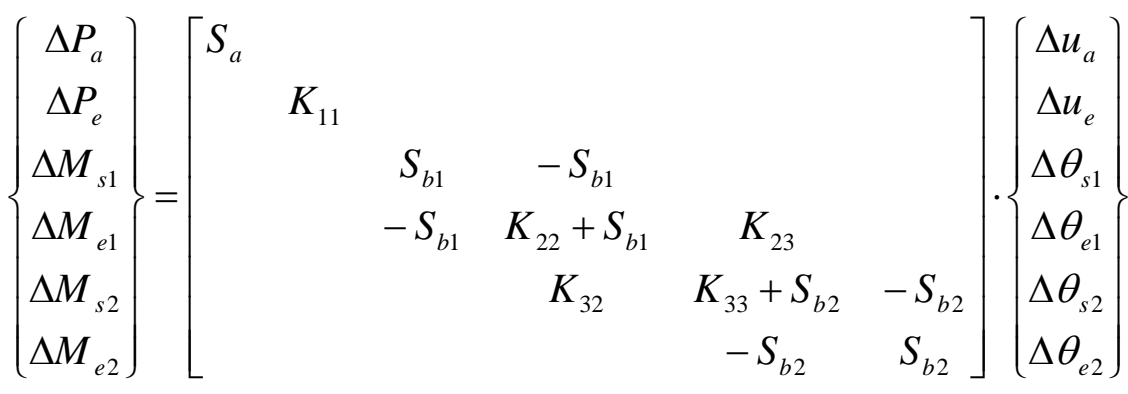

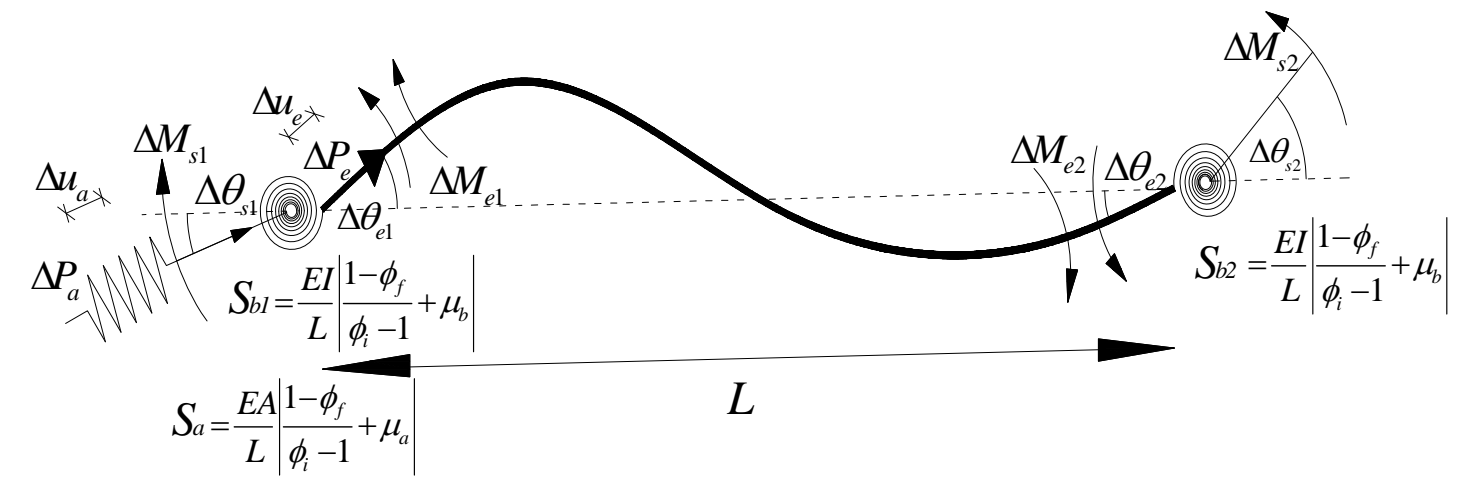

Figure 2. Beam-column element with axial and rotational springs

and for which it can be assumed that moment and axial force equilibrium of the beam-column element can be considered separately in regard to material yielding behaviour. Since a plastic hinge is inserted at the ends of the beam-column element, additional rotational degrees of freedom at the nodes $\Delta \theta_{s 1}$ and $\Delta \theta_{s 2}$ are introduced, as shown in Fig. 2. Using matrix condensation of the internal degree of freedom of the beam-column element $\left(\Delta M_{e 1}=\Delta M_{e 2}=0\right)$, Eq. 10 can be decomposed into

$\left\{\begin{array}{l}\Delta M_{s 1} \\ \Delta M_{s 2}\end{array}\right\}=\left[\begin{array}{ll}S_{b 1} & \\ & S_{b 2}\end{array}\right]\left\{\begin{array}{l}\Delta \theta_{s 1} \\ \Delta \theta_{s 2}\end{array}\right\}+\left[\begin{array}{ll}-S_{b 1} & \\ & -S_{b 2}\end{array}\right]\left\{\begin{array}{l}\Delta \theta_{e 1} \\ \Delta \theta_{e 2}\end{array}\right\}$

and

$\left\{\begin{array}{l}0 \\ 0\end{array}\right\}=\left[\begin{array}{cc}-S_{b 1} & \\ & -S_{b 2}\end{array}\right]\left\{\begin{array}{l}\Delta \theta_{s 1} \\ \Delta \theta_{s 2}\end{array}\right\}+\left[\begin{array}{cc}K_{11}+S_{b 1} & K_{12} \\ K_{21} & K_{22}+S_{b 2}\end{array}\right]\left\{\begin{array}{l}\Delta \theta_{e 1} \\ \Delta \theta_{e 2}\end{array}\right\}$.

After matrix condensation as in Eqs. 12 and 13, the incremental rotational deformations of the beam-column element $\Delta \theta_{\mathrm{e} 1}$ and $\Delta \theta_{\mathrm{e} 2}$ can be evaluated from the incremental joint rotations $\Delta \theta_{\mathrm{s} 1}$ and $\Delta \theta_{\mathrm{s} 2}$ from the equation 
$\left\{\begin{array}{l}\Delta \theta_{e 1} \\ \Delta \theta_{e 2}\end{array}\right\}=\left[\begin{array}{cc}K_{11}+S_{b 1} & K_{12} \\ K_{21} & K_{22}+S_{b 2}\end{array}\right]^{-1}\left[\begin{array}{cc}S_{b 1} & \\ & S_{b 2}\end{array}\right]\left\{\begin{array}{l}\Delta \theta_{s 1} \\ \Delta \theta_{s 2}\end{array}\right\}$,

or

$\left\{\begin{array}{l}\Delta \theta_{e 1} \\ \Delta \theta_{e 2}\end{array}\right\}=\frac{1}{|\mathrm{~K}|}\left[\begin{array}{cc}S_{b 1}\left(K_{22}+S_{b 2}\right) & -S_{b 2} K_{12} \\ -S_{b 1} K_{21} & S_{b 2}\left(K_{11}+S_{b 1}\right)\end{array}\right]\left(\begin{array}{c}\Delta \theta_{s 1} \\ \Delta \theta_{s 2}\end{array}\right)$

where $|\mathbf{K}|=\left(K_{11}+S_{s 1}\right) \cdot\left(K_{22}+S_{s 2}\right)-K_{12} K_{21}$. Once the element incremental rotations $\Delta \theta_{e 1}$ and $\Delta \theta_{e 2}$ are known from Eq. 14 which includes material non-linearity, the incremental bending resistance can be evaluated from

$\left\{\begin{array}{l}\Delta M_{e 1} \\ \Delta M_{e 2}\end{array}\right\}=\left[\begin{array}{ll}K_{11} & K_{12} \\ K_{21} & K_{22}\end{array}\right]\left\{\begin{array}{c}\Delta \theta_{e 1} \\ \Delta \theta_{e 2}\end{array}\right\}$

which is based on the elastic stiffness formulation based on elastic stiffnesses $K_{i j}$ because it is assumed that the element is elastic. Hence the equation

$\left\{\begin{array}{l}\Delta M_{e 1} \\ \Delta M_{e 2}\end{array}\right\}=\frac{1}{|\mathbf{K}|}\left[\begin{array}{ll}K_{11} & K_{12} \\ K_{21} & K_{22}\end{array}\right]\left[\begin{array}{cc}S_{b 1}\left(K_{22}+S_{b 2}\right) & -S_{b 2} K_{12} \\ -S_{b 1} K_{21} & S_{b 2}\left(K_{11}+S_{b 1}\right)\end{array}\right]\left(\begin{array}{l}\Delta \theta_{s 1} \\ \Delta \theta_{s 2}\end{array}\right)$

is equivalent to the incremental secant stiffness in the second-order elastic stiffness formulation in the companion paper [1]. For axial actions, the incremental force equilibrium equation is written separately as

$\left\{\begin{array}{l}\Delta P_{a} \\ \Delta P_{e}\end{array}\right\}=\left[\begin{array}{cc}S_{a} & 0 \\ 0 & K_{11}\end{array}\right]\left\{\begin{array}{l}\Delta u_{a} \\ \Delta u_{e}\end{array}\right\}=\left[\begin{array}{cc}S_{a} & 0 \\ 0 & E A / L\end{array}\right]\left\{\begin{array}{l}\Delta u_{a} \\ \Delta u_{e}\end{array}\right\}$,

where the incremental axial force in the linear spring $\Delta P_{a}$ is equal to the axial force in the beam-column element $\Delta P_{e}$. The total incremental axial deformation $\Delta u$ is the sum of the incremental axial deformation in the axial spring $\Delta u_{a}$ and in the element $\Delta u_{e}$, and consequently the axial resistance of an element can be expressed as

$\Delta P=\left(\frac{1}{S_{a}+E A / L}\right) \Delta u$

which describes the axial resistance of the element in terms of the axial displacement and so is equivalent to the secant stiffness for a plastic axial spring.

\subsection{Tangent Stiffness for Plastic Hinge Formulation}

For bending actions, the incremental moment-rotation relationship needs to be reformulated with respect to the nodal or local coordinate system, and the axial spring stiffness superimposed into the stiffness formulation in a similar way; it being assumed that the moment and axial force equilibrium conditions can be formulated separately. This produces 
$\left\{\begin{array}{c}\Delta P \\ \Delta M_{s 1} \\ \Delta M_{s 2}\end{array}\right\}=\left[\begin{array}{lll}K_{11}^{\prime} & & \\ & K_{22}^{\prime} & K_{23}^{\prime} \\ & K_{32}^{\prime} & K_{33}^{\prime}\end{array}\right]\left\{\begin{array}{c}\Delta u \\ \Delta \theta_{s 1} \\ \Delta \theta_{s 2}\end{array}\right\}$

where

$$
\begin{aligned}
& K_{11}^{\prime}=\frac{S_{a} K_{11}}{K_{11}+S_{a}}, \\
& K_{22}^{\prime}=\frac{1}{|\mathbf{K}|}\left[S_{b 1} K_{22}\left(K_{33}+S_{b 2}\right)-S_{b 2} K_{23}^{2}\right], \\
& K_{23}^{\prime}=K_{32}^{\prime}=\frac{1}{|\mathbf{K}|}\left[S_{b 2} K_{23}\left(K_{22}+S_{b 1}\right)-S_{b 2} K_{22} K_{32}\right], \\
& K_{33}^{\prime}=\frac{1}{|\mathbf{K}|}\left[S_{b 2} K_{33}\left(K_{22}+S_{b 1}\right)-S_{b 1} K_{32}^{2}\right] .
\end{aligned}
$$

Eq. 19 is equivalent to the tangent stiffness in the second-order elastic stiffness formulation in the companion paper [1]. This non-linear equilibrium path due to material non-linearities can be traced using the non-linear solution procedures described in the companion paper [1].

\section{NUMERICAL VERIFICATIONS}

In order to verify the accuracy and efficiency of the present non-linear second-order inelastic analysis, material non-linearities for an encastré beam with a concentrated load are compared with other inelastic analyses. Two benchmark solutions for frame structures are also investigated, including both material and geometric non-linearities, while a calibration frame is studied for investigating the effect of spreading of plasticity. Finally, a large-scale space framed structure is analysed using the proposed method.

\section{1. $\quad$ Encastré Beam with An Asymmetric Point Load}

A beam with fixed or encastré ends has been investigated to isolate a case which is governed by material yielding. The inelastic behaviour of this fixed beam with a residual stress of $60 \%$ of the yield stress was studied by Liew et al. [17], in which a point load was applied at one-third of the beam, as shown in Fig. 3. Plastic hinges then form in sequence, until a plastic mechanism is achieved (the load factor $\lambda_{p}=P L / M_{p}$ quoted in Trahair et al. [18] is 9.0 for a full plastic mechanism). Liew et al. [17] analysed this problem by both a refined plastic hinge method and a hinge-by-hinge method. The load factor $\lambda_{p}=P L / M_{p}$ is plotted against the dimensionless deflection $\delta \cdot E I / M_{P} L^{2}$ at the point of application of the load in Fig. 3. For the proposed non-linear analysis, two elements were used for the beam with the load being applied at span. It can be seen that the results of the present method are in accord with those of Liew et al. [17]. In the present non-linear analysis, initial yielding initiates at location 1 with a load factor $\lambda_{p 1}=5.41$; this hinge becomes fully plastic when $\lambda_{p 1}=8.81$. Fully-yielded plastic hinges form at locations 2 and 3 at values of $\lambda_{p 2}=8.91$ and $\lambda_{p 3}=9.01$. 


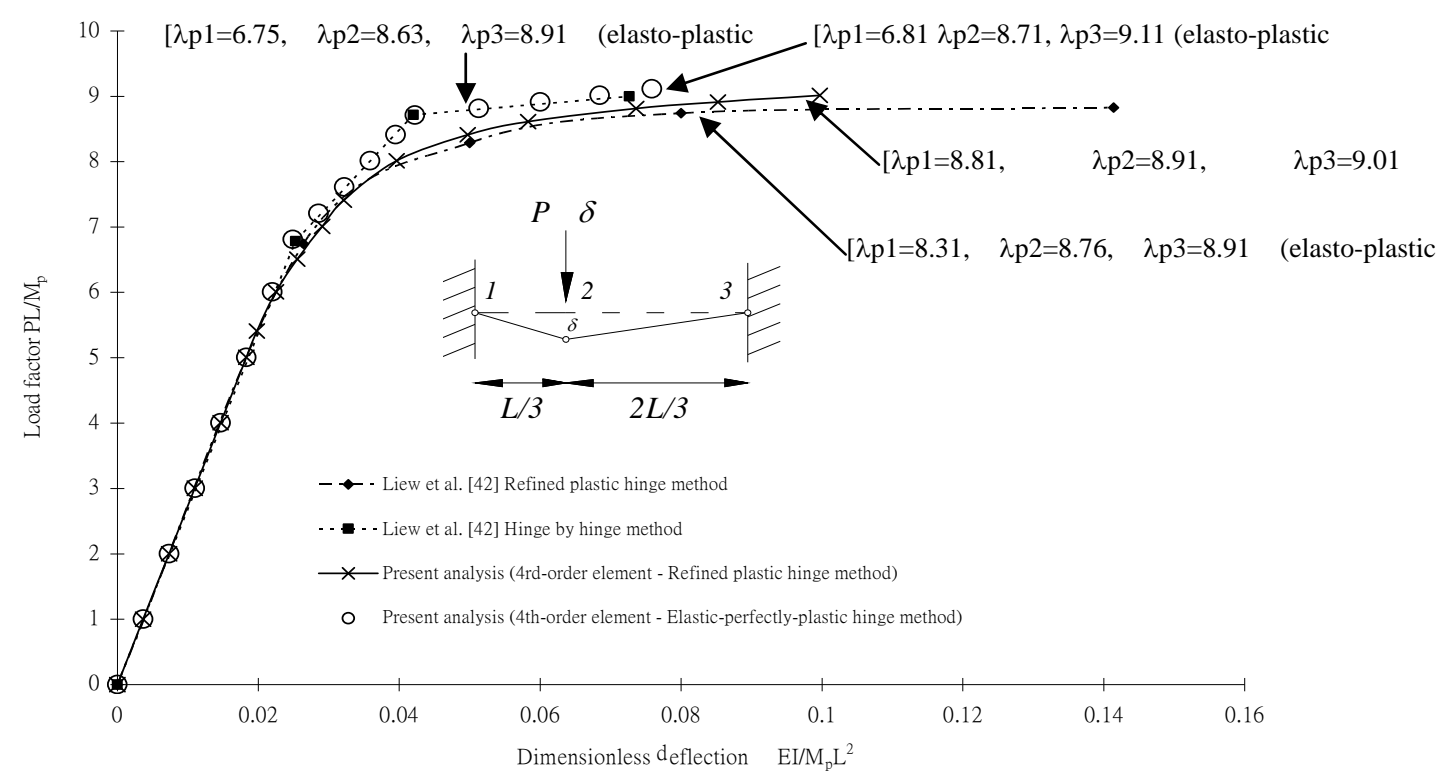

Figure 3. Normalized Load-displacement Curve of a Fixed-end Beam

Figure 3 also summarises the plastic load factors from various approaches. This numerical verification illustrates that the proposed plastic hinge method is able to model residual stresses, gradual yielding and fully-yielded material behaviour.

\subsection{Single-bay Frame of Vogel}

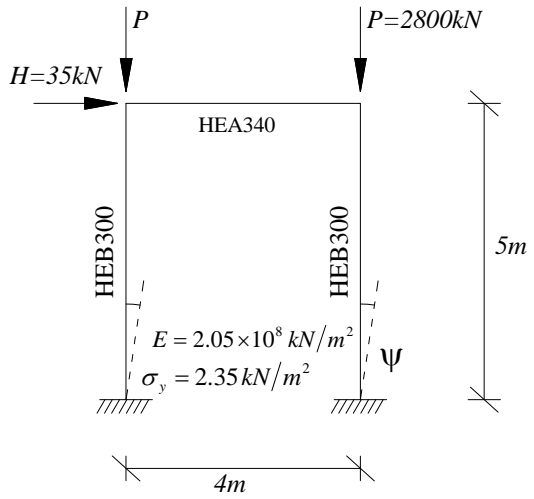

Figure 4. Geometric Configurations and Loading Pattern of Vogel’s Frame

The portal frame shown in Fig. 4 was analysed numerically in 1985 by Vogel [19], and this frame has been used by several researchers (e.g. Chan and Zhou [12] and Toma and Chen [20]) as a benchmark solution for including material non-linearities including residual stresses, gradual yielding and full-plasticity, as well as geometric non-linearities. Figure 4 shows the applied loading, material properties, member cross-section and geometry of the simple portal frame. The initial out-of-straightness $\psi=1 / 400$ of the column height was engaged in the plastic zone method [19]. The horizontal load on the top of the frame produces sway in the frame, and the vertical loads generate second-order effects in the columns. 


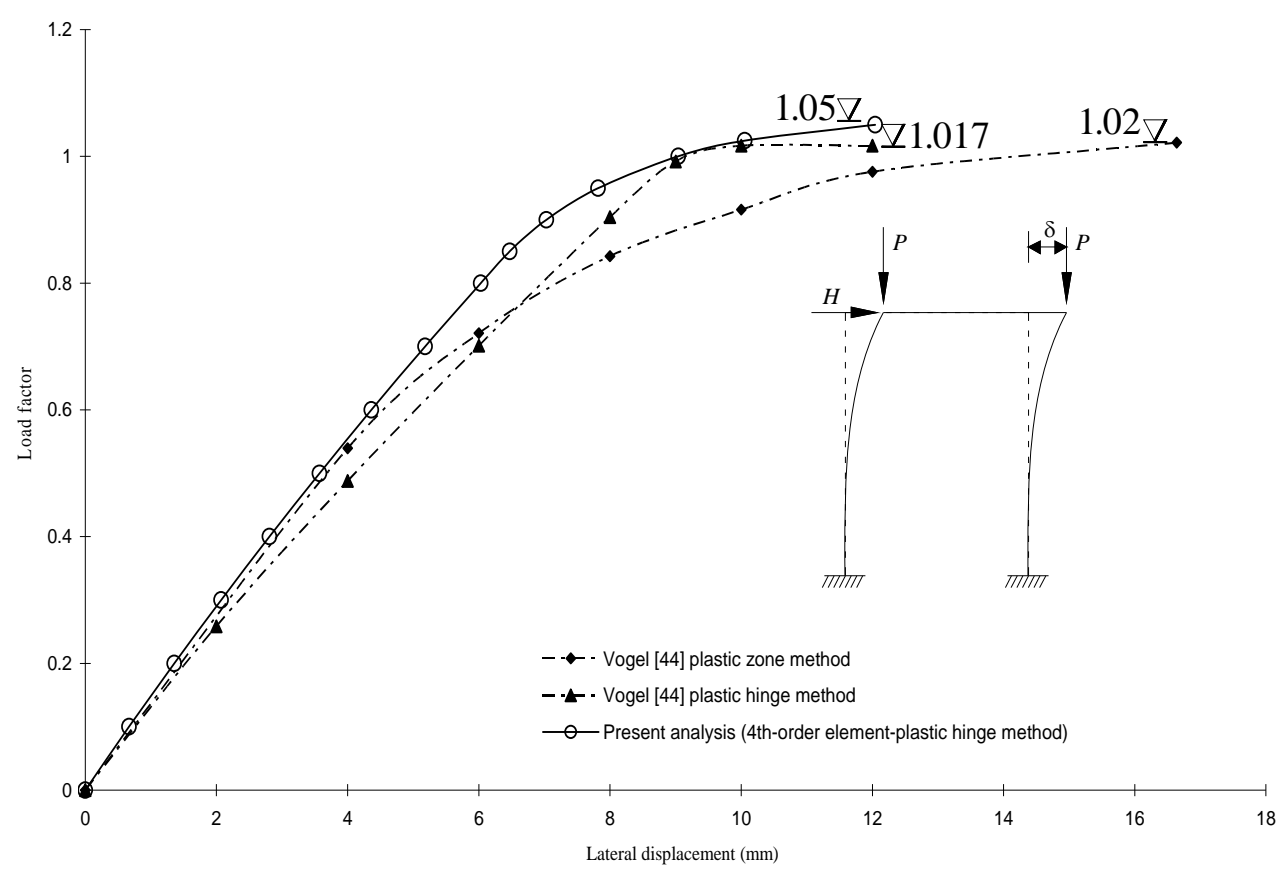

Figure 5. Load-displacement Curve at the Top of Vogel's Portal Frame

In the model herein, only one element was used to model each of the members, whereas Clarke [21] used a refined mesh with 50 elements for each column and 20 elements for the beam in his numerical modelling. More recently, Teh and Clarke [22] produced a more computationally efficient approach in their plastic zone method for which 4 elements were used in each column to model geometric non-linearity and stability effects, and one element for the beam. The present technique is still more computationally efficient than the latter modelling of Teh and Clarke [22].

The load versus displacement curves for the top of the column from both the approach of this paper and that of Vogel [19] are shown in Fig. 5. Generally, the load-displacement behaviour from the present method is reasonably consistent with that of Vogel, the deviation between the present analysis and Vogel's plastic zone method being attributed mainly to the different onsets of initial yielding at load factors of 0.8 and 0.6 respectively. The plastic hinge formulation of Vogel does not include gradual yielding. The ultimate load factor from the analysis of this paper is 1.05, whereas that from Vogel's plastic zone analysis is 1.02 and Vogel's plastic hinge analysis is 1.07. All of these three methods produce a consistent ultimate load factor.

Initial yielding occurs firstly in the right column at its bottom at a load factor of 0.825 , and all four joints of the frame have reached initial yield at a load factor of 0.875 . When the frame is loaded to a load factor of 1.05, a fully yielded plastic hinge forms in the right column at its bottom, and with an infinitesimal increase of this load factor, a failure mechanism develops in the frame. The portal frame exhibits no strength reserve from its threefold redundancy because of the symmetric loading distribution in this frame; when the fully yielded plastic hinge is formed, the other three hinges for which full yielding is imminent form fully plastic hinges in the next iteration with numerical divergence being detected at a load factor of 1.05. This represents the ultimate capacity of the frame. The lateral behaviour of the frame from the present approach is stiffer than the results of Vogel [19], probably because of the different initial yielding conditions which are engaged in both analyses. This benchmark numerical example is used commonly as a countercheck of gradual yielding behaviour. 


\subsection{Six Storey Rigid-jointed Frame of Vogel}

The two-bay six-storey European calibration frame shown in Fig. 6 was subjected to proportionally applied distributed gravity loads and to concentrated loads, and its behaviour was reported by Vogel [19]. The member sections and frame geometry are depicted in Fig. 6, and the elastic modulus and yield stress of the steel were taken as $2.05 \times 10^{8} \mathrm{kN} / \mathrm{m}^{2}$ and $2.35 \times 10^{5} \mathrm{kN} / \mathrm{m}^{2}$ throughout. The initial out-of-straightness of the frame was assumed to be $\psi=1 / 450$, with all members being rigidly connected at their joints. In the modelling of this frame, each column was discretised as one element whilst the beams were subdivided into four elements because only nodal loads are admitted, although the present formulation does allow for a quadratic bending moment distribution to be simulated in by the fourth-order finite element. It is worth noting that using the plastic zone approach [21], each column was subdivided into 20 elements and each beam into either 20 or 40 elements, depending on the degree of non-linearity.

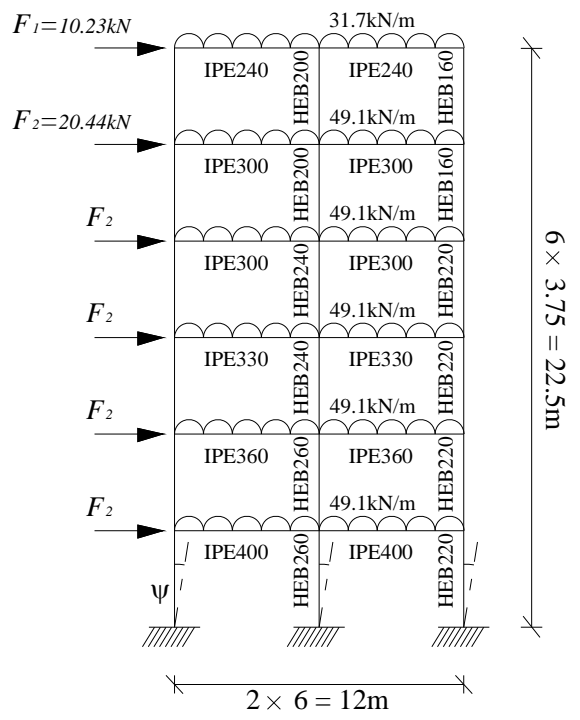

Figure 6. Geometric Configuration and Loading Pattern of Vogel's six-storey Frame

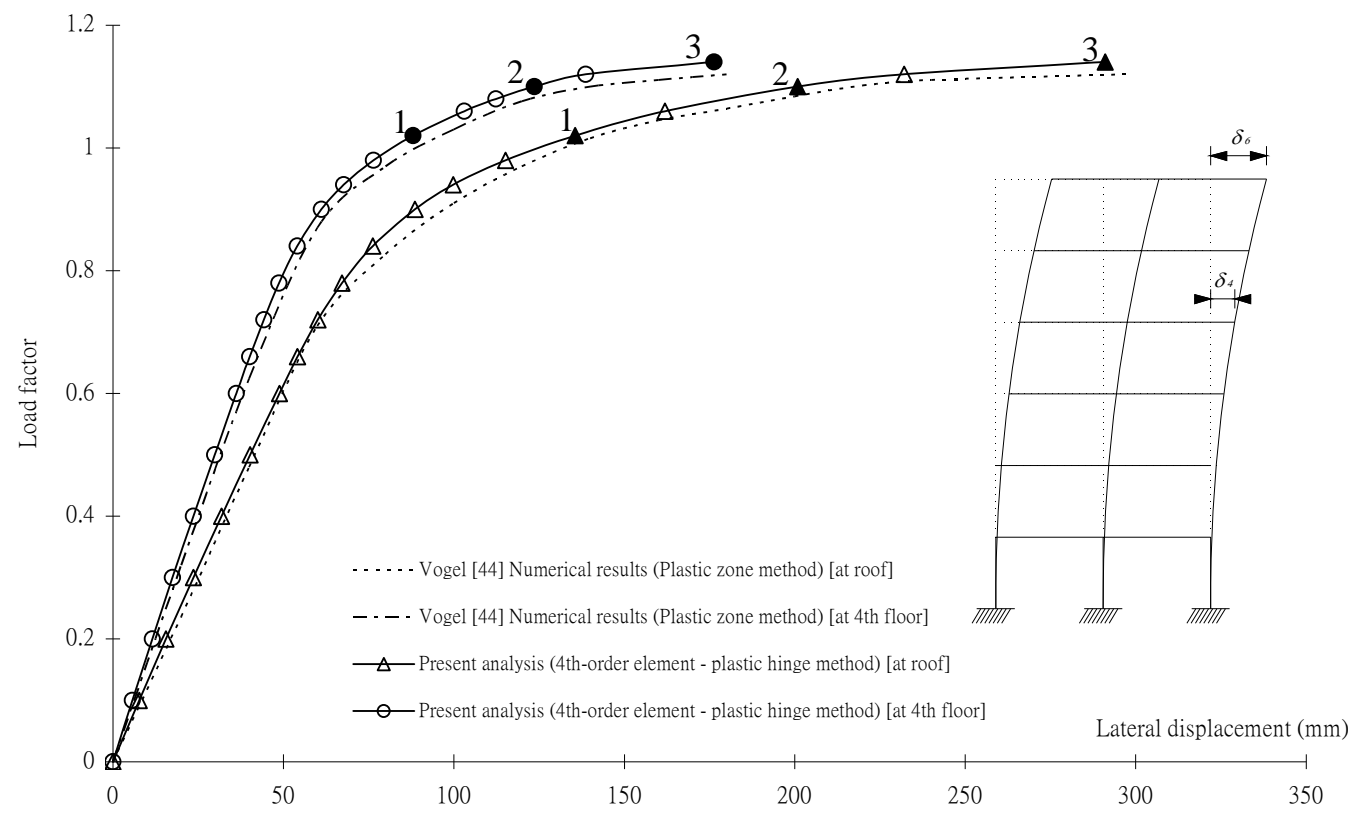

Figure 7. Lateral Drifts of the Vogel's six-storey Frame 
Figure 7 shows the lateral drifts of the $4^{\text {th }}$ and $6^{\text {th }}$ floors of the frame determined from the analysis of this paper, and those reported by Vogel [19], and it can be seen that they are in excellent agreement. The ultimate load factor predicted by the current method is 1.14 , which is slightly higher than the value of 1.12 given by Vogel [19].

In the approach of this paper, initial yielding occurs at a load factor of 0.62 at the beams adjacent to the interior column joints at the $4^{\text {th }}$ and $6^{\text {th }}$ floor levels. Both of these hinges have fully yielded when a load factor of 0.94 is reached, which heralds the onset of non-linearity which can be seen in Fig. 7. At a load factor of 1.02 in Fig. 7, the number of fully-yielded plastic hinges increases to four, and these are denoted by the numeric index 1 in Fig. 8a and in Fig. 7. When the frame is loaded further to a load factor of 1.10, a total of 10 fully-yielded plastic hinges have formed and the additional ones are denoted by the index 2 in Fig. 8a and in Fig. 7. When the ultimate load of the frame has been reached, there are a total of 23 fully-yielded plastic hinges, those formed at the beams' mid-spans are due mainly to gravity loading, whereas those formed at the beams' ends are a result of the effect of sway in accordance with the distribution of bending moment at ultimate loading which is shown in Fig. 8b. This verification example indicates that the present inelastic approach can accurately replicate the effects of gradual yielding and full plasticity in a large-scale multi-storey steel frame. Ziemian [23] also carried out a calibration study of this frame in his numerical analysis in 1992. It is worth noting that the following comparison is for information only because of different computational technologies being used. While Ziemian's plastic zone approach took 8 minutes to perform the analysis, the present analysis took 4 seconds on a desktop personal computer. The present plastic hinge analysis is more efficient by comparison and can capture the real inelastic and stability behaviour of large-scale frames accurately, including initial yield, gradual or partial yield and full plasticity, as well as frame sway and member bowing.

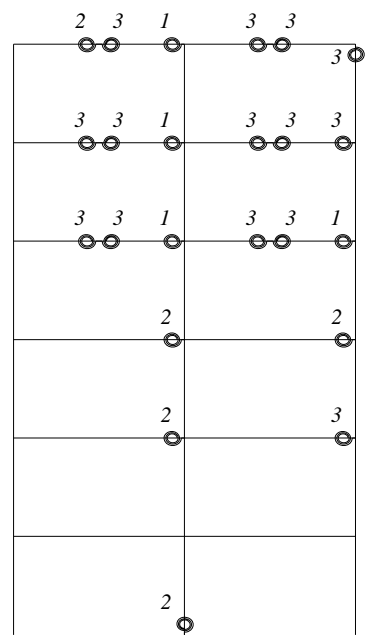

a) Locations of the fully plastic

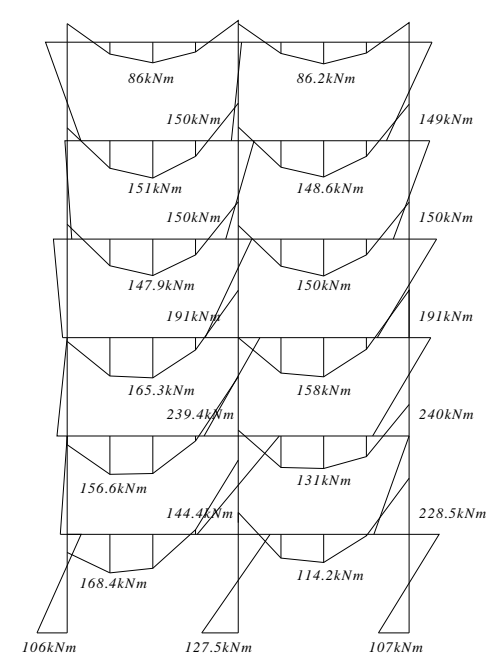

b) Moment distribution on the

Figure 8. Plastic Hinge Pattern and Moment Distribution on the Frame

\subsection{Two-storey Asymmetric Calibration Frame}

The two-storey two-bay asymmetrical frame subjected to vertical loading only shown in Fig. 9 was studied in 1982 by Iffland and Birnstiel [24] as part of the American Institute of Steel Construction report on frame stability with plasticity. This calibration frame was chosen as a benchmark for validating the loading redistribution due to plasticity. The material modelling used was elastic-perfectly-plastic (without strain hardening), and the geometry, material properties, loading and section configurations are shown in Fig. 18. Ziemian [23] and Clarke [21] also analysed this frame in the verification of their numerical analyses. Ziemian [23] presented both plastic zone 
and hinge methods, in which he used 60 elements per beam and 50 elements per column in his modelling, while Clarke [21] undertook a plastic zone method analysis of the frame with each column being subdivided into 20 elements, beams B1 and B3 into 20 elements and beams B2 and B4 into 40 elements. However, modelling the frame using the approach of this paper necessitated subdividing the columns into one element beams into 4 elements to include the distributed loading, as discussed previously. Both arc-length [25] and residual load [26] strategies are proposed to trace the non-linear equilibrium solution of this two-storey asymmetrical frame.

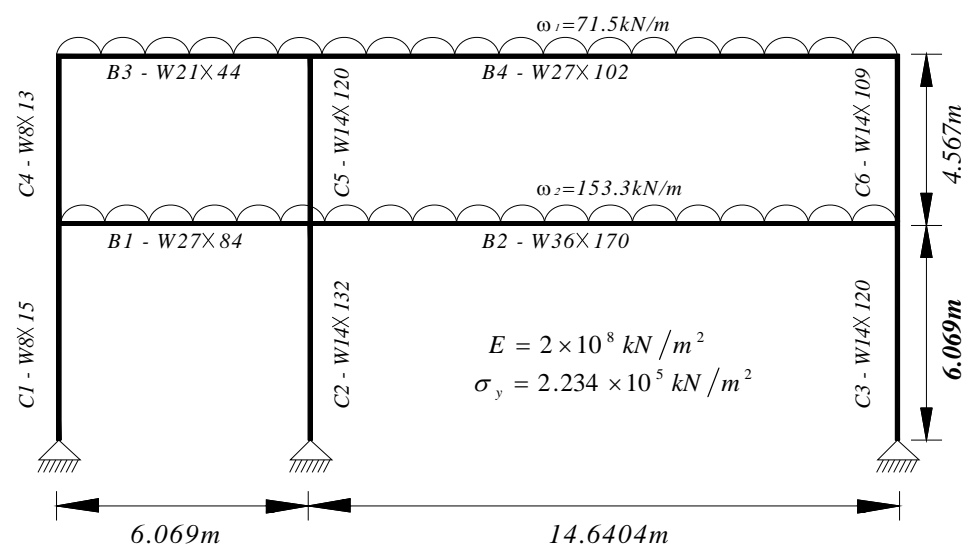

Figure 9. Configurations of the American Calibration Frame

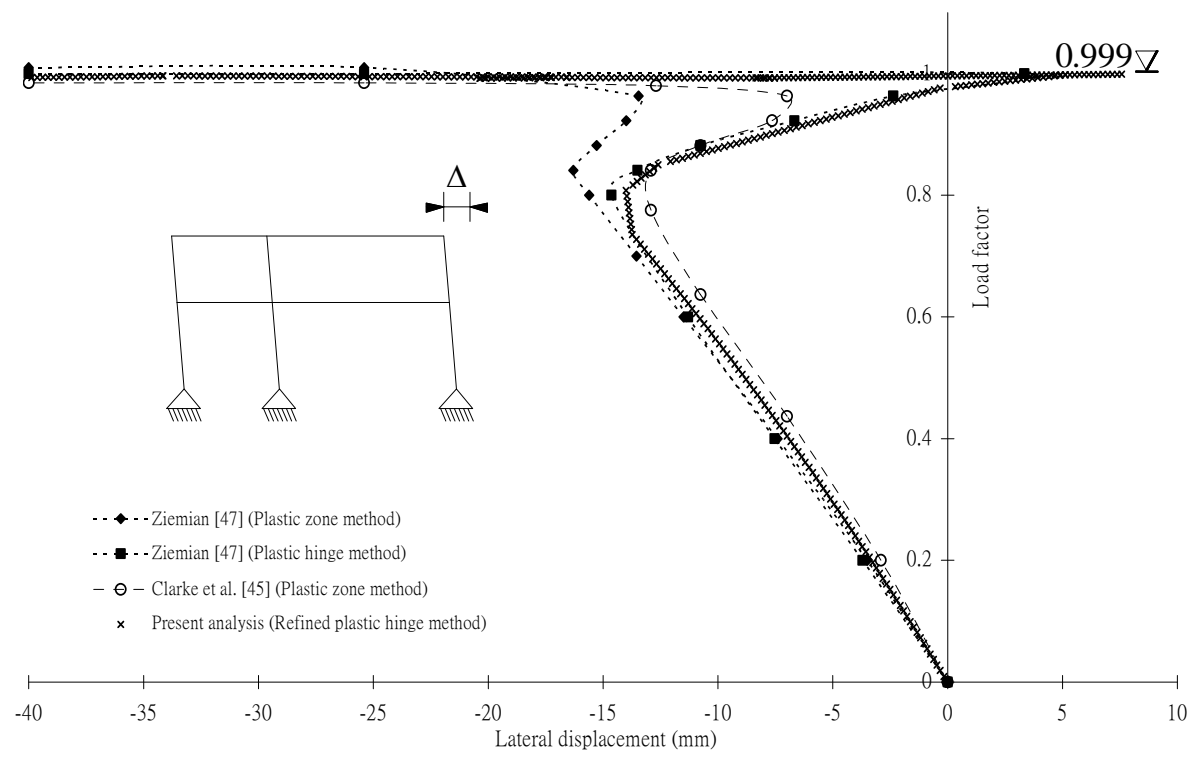

Figure 10. Lateral Displacement at Top of the Two-storey Frame Against Load Factor

The lateral displacement of the frame at the roof level $\Delta$ is plotted in Fig. 10 against the load factor. The lateral displacement from the method of this paper agrees almost completely with the plastic hinge method [23] throughout the entire loading range. Columns C1 and C4 are much more flexible than the other columns of the frame, and so initially the frame sways towards its weaker bay as shown in Fig. 10. At a load factor of about 0.808, three plastic hinges are formed as shown in Fig. 11, with the differential yielding between the stronger and weaker bays causing their relative stiffnesses to change, with a consequent change in the direction of the sway $\Delta$, as shown in Fig. 10. Using the present non-linear analysis, the plastic hinges form subsequently with an increase in load until the ultimate load factor $\left(\lambda_{u}=0.999\right)$ is reached, with the hinges shown in Fig. 11, but before doing so the sway reverses its direction again due to the significant yielding of the stronger bay, in which plastic hinges form at the mid-span of beams B2 and B4. The ultimate load factor of $\lambda_{u}=$ 0.999 compares very well with that of Ziemian [23] $\left(\lambda_{u}=1.01\right)$ and Clarke [21] $\left(\lambda_{u}=0.985\right)$. The numerical analysis proposed herein was completed in 6 seconds for 300 load cycles. 


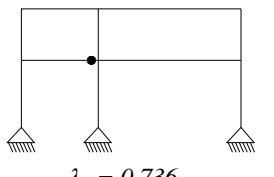

$\lambda_{p}=0.736$

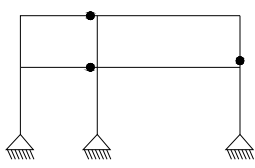

$\lambda_{p}=0.808$

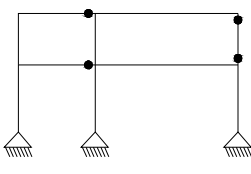

$\lambda_{p}=0.85$

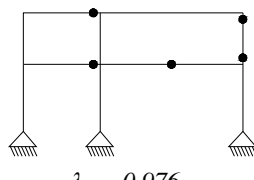

$\lambda_{p}=0.976$

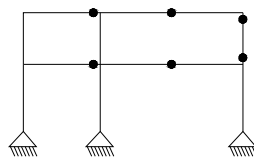

$\lambda_{p}=0.998$

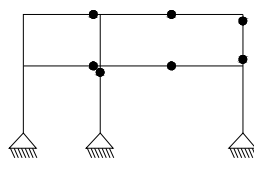

$\lambda_{p}=0.999$

Figure 11. Sequence of Plastic Hinges Formed at Corresponding Plastic Load Factors

\subsection{6-storey Large Space Frame Structure}

The rigid-jointed 6-storey asymmetrical space frame shown in Fig. 12 was proposed and analysed by Orbison et al. [27], and later by Liew et al. [28] and Jiang et al. [29]. The yield strength and elastic modulus were taken as $250 \times 10^{5} \mathrm{kN} / \mathrm{m}^{2}$ and $2.07 \times 10^{8} \mathrm{kN} / \mathrm{m}^{2}$ respectively, and the frame was subjected to both uniform gravity loads of $9.6 \mathrm{kN} / \mathrm{m}^{2}$ on each floor and lateral loads of $53.376 \mathrm{kN}$ which were applied at every beam-column joint in the transverse z-direction, as shown in Fig. 12. The member sections and plan configuration of the floors are also shown in Fig. 12. In the present numerical modelling, one element was used for each member to replicate the overall load-displacement behaviour of the space frame, which is the same as used in [28, 29]. The main differences in these analyses is in the treatment of inelasticity; a plastic hinge model using a plastic interaction function was employed by Orbison et al. [27] and by Liew et al. [28], whereas a plastic zone approach with gradual member yielding was used by Jiang et al. [29]. The refined plastic hinge approach in the present method allows for gradual yielding at the hinge under both axial and bending actions.
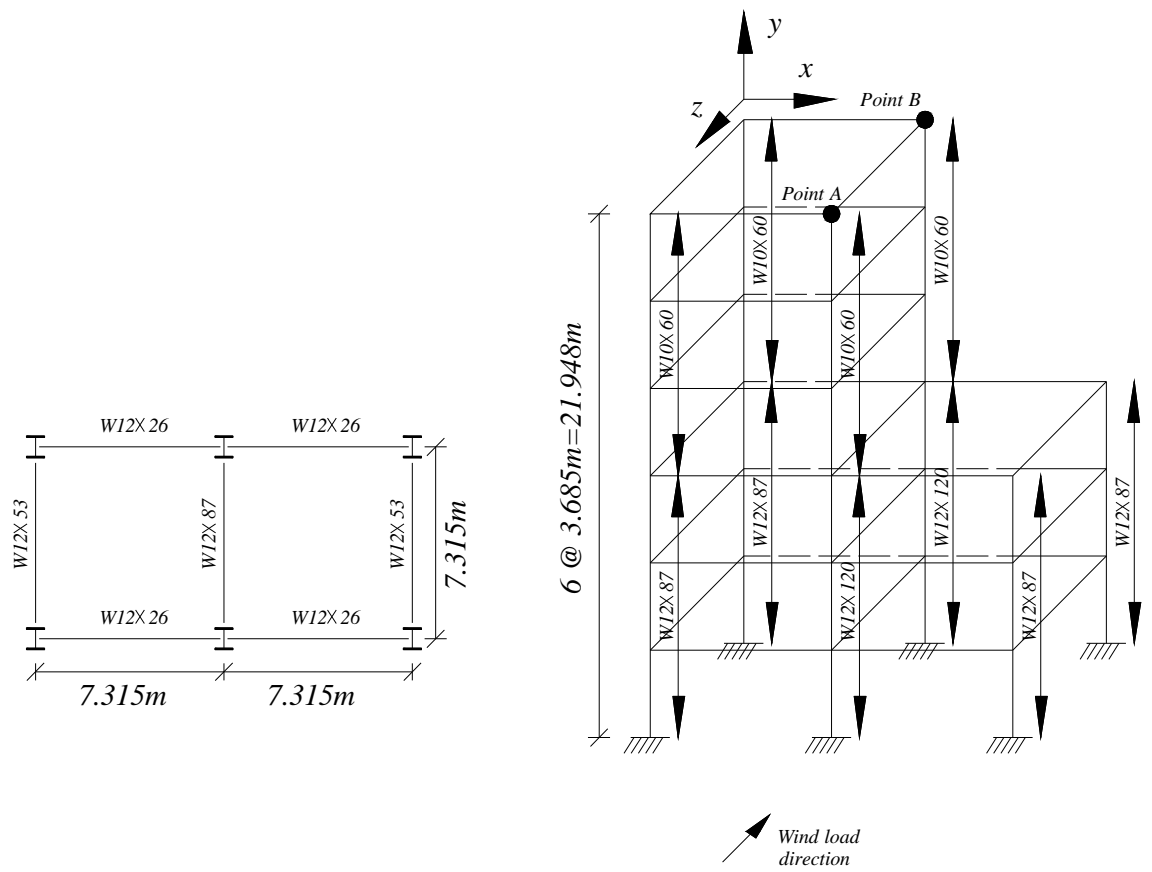

Figure 12. Section and geometric configuration of 6-storey space framed structure 


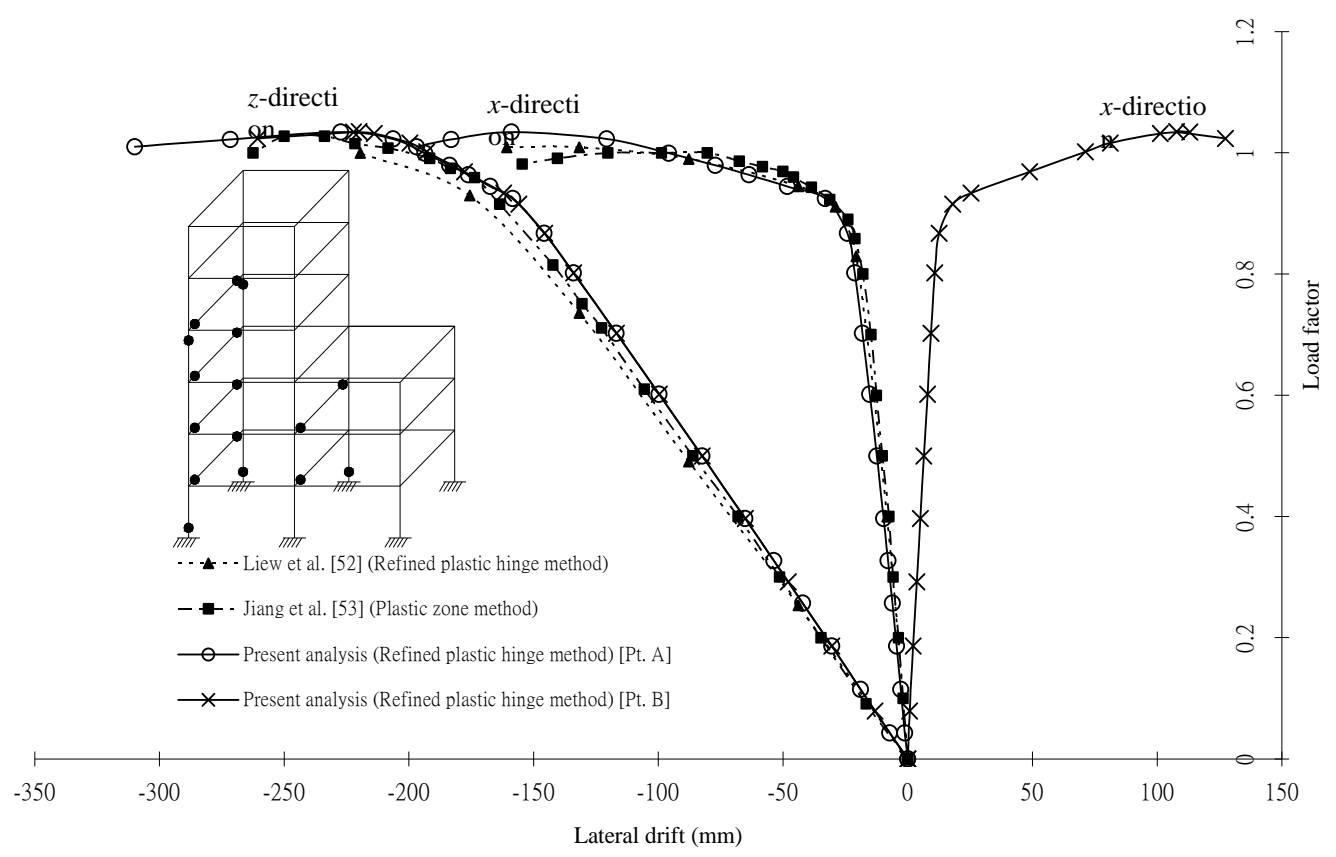

Figure 13. Lateral drifts of points A and B in $x$ - and $z$-directions vs load factor

Figure 13 plots the lateral drifts at points $\mathrm{A}$ and $\mathrm{B}$, which are shown as black dots in Fig. 12, in the $x$ and $z$-directions against the load factor. In [28, 29], the lateral displacements of point $\mathrm{A}$ are completely consistent in all ranges with the results of the present non-linear analysis. The present analysis predicts initial frame yielding at a load factor of 0.835 ; the ultimate load factor of the space frame from [28] is 1.005 whereas a value of 1.0344 is predicted from the present approach. In Fig. 13 , it can be seen that the lateral displacement of point B in the $x$-direction is antisymmetric to that of point A, whilst the lateral displacements for points A and B are the same in the z-direction. This implies that the structure twists as the applied loads and structural form are asymmetrical because of the change of the structural plan at the fourth floor level. In addition, after sufficient plastic hinges have formed at a load factor of about 0.92, the space frame undergoes large lateral displacements in both transverse directions and the present non-linear analysis predicts the formation of 16 plastic hinges at the ultimate load factor of 1.0344. The locations of the plastic hinges are shown by the dots in Fig. 13, indicating the yielding which occurs at the ends of the beams in the 6-sotrey space frame due to the torsional effect on the whole structure. In [28], a total of 20 plastic hinges developed and most of them were located at the fourth floor owing to the twisting of this space structure. In summary, the general material and geometric non-linear behaviour of the large-scale space structure is adequately captured using the present non-linear analysis.

\section{CONCLUDING REMARKS}

In this paper, a refined plastic hinge method has been proposed to account for material non-linearities in steel framed structures. The formulation makes recourse to a gradual yielding from prescribed initial and fully-yielded interaction criteria in terms of force resultants (axial and bending actions), so that distributed plasticity across the element section is adequately modelled. This proposed refined plastic hinge formulation is incorporated into the non-linear elastic stiffness analysis described in the companion paper. The technique has been applied to a number of independent sample problems, with good agreement being obtained, and moreover the solutions were obtained very rapidly. 
Both this and the companion paper demonstrate that the present fourth-order stiffness formulation with a refined plastic hinge methodology can accurately tackle material yielding and structural instability, using a minimum of element discretisations by comparing with the conventional finite element in deference to the plastic zone method. The technique provides an efficacious and reliable means for the analysis of general steel structures numerically, when they have many members, accounting adequately for geometric and material non-linear effects. Further, the present plastic hinge stiffness formulation is able to evolve itself accounting for the various kinds of materials versatilely, such as concrete or composite, once the failure surfaces in the hinge stiffness are replaced correspondingly. This paper therefore offers a non-linear analysis with accuracy in solution, versatile for vast forms of structures and efficiency in convergence for engineering practice.

\section{ACKNOWLEDGEMENT}

The work in this paper was supported by the Australian Research Council through a Federation Fellowship awarded to the second author.

\section{REFERENCES}

[1] Iu, C.K. and Bradford, M.A., "Higher-order Non-linear Analysis of Steel Structures”, Part 1: Elastic second-order formulation, (???? Year).

[2] King, W.S., White, D.W. and Chen, W.F., "On Second-order Inelastic Analysis Methods for Steel Frame Design”, Journal of Structural Engineering, ASCE, 1992, Vol. 118, No. 2, pp. 408-428.

[3] Duan, L. and Chen, W.F., "Design Interaction Equation for Steel Beam-columns”, Journal of Structural Engineering, ASCE, 1989, Vol. 115, No. 5, pp. 1225-1243.

[4] Liew, J.Y.R., White, D.W. and Chen, W.F., "Second-order Refined Plastic-hinge Analysis for Frame Design”, Part I, Journal of Structural Engineering, ASCE, 1993, Vol. 119, No. 11, pp. 3196-3216.

[5] Liew, J.Y.R., White, D.W. and Chen, W.F., "Second-order Refined Plastic-hinge Analysis for Frame Design”, Part II, Journal of Structural Engineering, ASCE, 1993, Vol. 119, No. 11, pp. 3217-3237.

[6] American Institute of Steel Construction, Load and Resistance Factor Design Specification for Structural Steel Buildings, AISC, Chicago, 1986.

[7] Yau, C.Y. and Chan, S.L., "Inelastic and Stability Analysis of Flexibly Connected Steel Frames by Springs-in-series Model”, Journal of Structural Engineering, ASCE, 1994, Vol. 120, No. 10, pp. 2803-2819.

[8] Chan, S.L. and Chui, P.P.T., “A Generalized Design-based Elastoplastic Analysis of Steel Frames by Section Assemblage Concept”, Engineering Structures, 1997, Vol. 19, No. 8, pp. 628-636.

[9] Iu, C.K. and Chan, S.L., "A Simulation-based Large Deflection and Inelastic Analysis of Steel Frames under Fire”, Journal of Constructional Steel Research, 2004, Vol. 60, pp. 1495-1524.

[10] Iu, C.K., Chan, S.L. and Zha, X.X., "Material Yielding by Both Axial and Bending Spring Stiffness at Elevated Temperature”, Journal of Constructional Steel Research, 2007, Vol. 63, pp. 677-685.

[11] Zhou, Z.H. and Chan, S.L., "Elastoplastic and Large Deflection Analysis of Steel Frames by One Element per Member I: One Hinge along Member,” Journal of Structural Engineering, ASCE, 2004, Vol. 130, No. 4, pp. 538-544. 
[12] Chan, S.L. and Zhou, Z.H., "Elastoplastic and Large Deflection Analysis of Steel Frames by One Element per Member II: Three Hinges along Member", Journal of Structural Engineering, ASCE, 2004, Vol. 130, No. 4, pp. 545-553.

[13] Kassimali, A., "Large Deformation Analysis of Elastic-plastic Frames," Journal of Structural Engineering, ASCE, 1983, Vol. 109, No. 8, pp. 1869-1886.

[14] Tebedge, N. and Chen, W.F., "Design Criteria for H-columns under Biaxial Loading", Journal of the Structural Division, ASCE, 1974, Vol. 100(ST3), pp. 579-598.

[15] Iu, C.K., Bradford, M.A. and Chen, W.F., "Second-order Inelastic Analysis of Composite Framed Structures based on the Refined Plastic Hinge Method”, Engineering Structures, 2009, Vol. 31, No. 3, pp. 799-813.

[16] Iu, C.K., "Inelastic Finite Element Analysis of Composite Beams on the Basis of the Plastic Hinge Approach”, Engineering Structures, 2008, Vol. 30, pp. 2912-2922.

[17] Liew, J.Y.R., White, D.W. and Chen, W.F., "Second-order Refined Plastic Hinge Analysis of Frames”, Structural Engineering Report CE-STR-92-12, Purdue University, West Lafayette, Indiana, 1992.

[18] Trahair, N.S., Bradford, M.A., Nethercot, D.A. and Gardner, L., "The Analysis and Behaviour of Steel Structures to EC4”, 4 ${ }^{\text {th }}$ edn., Taylor and Francis, London, 2008.

[19] Vogel, U., “Calibrating Frames”, Der Stahlbau 1985, Vol. 10, pp. 296-301.

[20] Toma, S. and Chen, W.F., "European Calibration Frames for Second-order Inelastic Analysis”, Engineering Structures 1992, Vol. 14, No. 1, pp. 7-14.

[21] Clarke, M.J., "Plastic Zone Analysis of Frames", In: Advanced Analysis of Steel Frames, Chen, W.F. and Toma, S., eds., CRC Press, Boca Raton, Florida, 1994, pp. 259-320.

[22] Teh, L.H. and Clarke, M.J., "Plastic-zone Analysis of 3D Steel Frames using Beam Elements”, Journal of Structural Engineering, ASCE, 1999, Vol. 125, No. 11, pp. 1328-1337.

[23] Ziemian, R.D., “A Verification Study for Methods of Second-order Inelastic Analysis”, Proceedings of Annual Technical Session, Structural Stability Research Council, Pittsburgh, Pennsylvania, 1992, pp. 315-326.

[24] Iffland, J.S.B. and Birnstiel, C., "Stability Design Procedures for Building Frameworks", Research Report, AISC Project No. 21.62, American Institute of Steel Construction, Chicago, Illinois, 1982.

[25] Crisfield, M.A., "An Arc-length Method including Line Searches and Accelerations”, International Journal for Numerical Methods in Engineering, 1983, Vol. 19, pp. 1269-1289.

[26] Chan, S.L., "Geometric and Material Nonlinear Analysis of Beam-columns and Frames using the Minimum Residual Displacement Method”, International Journal for Numerical Methods in Engineering 1988, Vol. 26, pp. 2657-2669.

[27] Orbison, J.G., McGuire, W. and Abel, J.F., "Yield Surface Applications in Nonlinear Steel Frame Analysis”, Computer Methods in Applied Mechanics and Engineering 1982, Vol. 33, No. 1, pp. 557-573.

[28] Liew, J.Y.R., Chen, H., Shanmugam, N.E. and Chen, W.F., "Improved Nonlinear Plastic Hinge Analysis of Space Frame Structures”, Engineering Structures, 2000, Vol. 22, No. 2, pp. 1324-1338.

[29] Jiang, X.M., Chen, H. and Liew, J.Y.R., "Spread of Plasticity Analysis of Three-dimensional Steel Frames”, Journal of Constructional Steel Research, 2002, Vol. 58, pp. 193-212. 